\title{
Emerging needs, evolving services: the health of Pacific peoples in New Zealand
}

\author{
SARAH WRIGHT \\ Department of Management \\ College of Business and Economics \\ University of Canterbury \\ Private Bag 4800 \\ Christchurch 8140, New Zealand \\ ANDREW HORNBLOW \\ Health Sciences Centre \\ University of Canterbury \\ Private Bag 4800 \\ Christchurch 8140, New Zealand
}

\begin{abstract}
From $0.1 \%$ of the total population in 1945 to $6.9 \%$ in 2006, Pacific peoples now resident in New Zealand highlight significant health policy and service delivery issues within an increasingly diverse society. Over the last decade, marked differences in the health status of Pacific New Zealanders and Palagi New Zealanders have been well documented, showing high levels of disparity and continuing negative trends. This paper provides a broad overview of the history of Pacific health and health initiatives in New Zealand from the 1940s through to the mid 2000s, highlighting the interface between Pacific peoples and the New Zealand health sector. While the New Zealand Government has become increasingly responsive to Pacific health needs, significant disparities remain between Pacific and Palagi populations. Furthermore, many of the encouraging health initiatives introduced in the past decade remain at risk due to a variety of factors, including a need to strengthen the Pacific health workforce and management expertise.
\end{abstract}

Keywords Pacific health; Pacific peoples; New Zealand health services; health status; health disparities

\section{INTRODUCTION}

The Pacific descent population is an increasingly significant immigrant population in New Zealand and includes people originally from Samoa, the Cook Islands, Niue, Tonga, Tokelau, Papau New Guinea, Vanuatu, Fiji, Solomon Islands, Tuvalu, Kiribati, Nauru, and French Polynesia. According to the 2006 census data, approximately $6.9 \%$ of the resident New Zealand population is made up of people belonging to Pacific ethnic groups. The Pacific population in New Zealand consists of at least 20 distinct languages and cultural groups. The Samoan 
community is the largest $(50 \%)$, followed by Cook Islanders $(22.5 \%)$, Tongan $(15.5 \%)$, Niuean (9\%), Fijian (2\%), and Tokelauean (1\%). Contrary to the common notion of Pacific homogeneity in New Zealand, there is no generic "Pacific community". Rather, Pacific peoples align themselves variously along ethnic, geographic, church, family, school, birthplace, or occupational lines (Ministry of Education 2001).

Increasing statistical evidence supports the view that, overall, Pacific peoples are disadvantaged compared with other populations in New Zealand across a range of socio-economic factors (Ministry of Pacific Island Affairs 1999a). In terms of overall health status, Pacific people generally fare poorly compared with Palagi New Zealanders. Over the past decade, marked differences in the health status of Pacific New Zealanders and Palagi New Zealanders have been well documented showing high levels of disparity and continuing negative trends (Ministry of Health 2003a, 2004, 2007). These differences are observed in mortality and morbidity rates, excess deaths, and various health factors (Ministry of Health 2005). The Pacific Health Chart Book, produced by the Ministry of Health in 2004, shows the leading contributors of poor health amongst Pacific peoples in New Zealand to be cardiovascular disease, diabetes, injuries, respiratory diseases, cancers (lung cancer and primary liver cancer among men; breast cancer and cervical cancer among women), and infectious diseases. Life expectancy of Pacific males is 4.8 years shorter than the average for New Zealand and 4.4 years shorter for Pacific females.

As with other human processes, health needs and health status change over time. The purpose of this paper is to provide a general overview of the history of Pacific health and Pacific health services in New Zealand, including the interface between Pacific peoples and the New Zealand health sector. Historical analysis of the health status of Pacific peoples and the provision of health services in New Zealand will help to inform us of future health needs as demographic, socio-economic factors, and service provision change. The Pacific population, with its younger and increasingly New Zealand-born profile, is projected to increase to $12 \%$ of New Zealand's population by 2051. Given the historic under-counting that has been shown to exist in Pacific peoples (Edwards 1996), this is perhaps a conservative estimate. However, under-counting is likely to be a less significant issue as the New Zealand-born proportion of the Pacific population increases. Addressing the health needs of Pacific peoples, and their potential to contribute to New Zealand society and the New Zealand workforce, is a priority issue.

\section{POST-1940 MIGRATION OF PACIFIC PEOPLES TO NEW ZEALAND}

Pacific peoples in New Zealand share a common migration and assimilation (Ministry of Pacific Island Affairs 1999a) although there were some significant differences (Cook Islanders, Niueans, and Tokelauans had a different status as New Zealand citizens). In 1945, Pacific people in New Zealand made up just $0.1 \%$ of the total population. However, in the years following World War II, New Zealand experienced a significant period of industrial expansion. As a consequence, immigration was needed to fill labour shortages generated by this growth. Immigration restrictions were subsequently relaxed, encouraging Pacific peoples to migrate to New Zealand for work opportunities. By the 1950s, the immigration policies were liberalised even further to fill chronic labour shortages, with workers from the Pacific Islands recruited to work in industrial production. During the 1960s, immigration targets were increased and 
temporary labour migration from the South Pacific started to increase rapidly (Krishnan et al. 1994). Migrants from the Pacific Islands were initially motivated to come to New Zealand for economic reasons, providing the means to earn higher wages and to provide financial support to family who remained in the home country. Pacific migrant workers were brought to New Zealand and employed primarily as production line workers on vehicle and domestic appliance assembly lines. Others occupied positions in the service sector, such as hospital kitchen hands and laundry workers.

The New Zealand Government instituted several immigration schemes to encourage workers from the Pacific Islands to migrate to New Zealand. For example, a quota system introduced in 1962 admitted 1000 immigrants per year from Western Samoa, and a Tokelauan resettlement programme was initiated in response to hurricane devastation, overcrowding, and limited opportunities in Tokelau. In 1967, the then Prime Minister, Sir Keith Holyoake, announced a plan to recruit 100 Tongan workers every 6 months for industrial firms located in the Hutt Valley. The workers were issued with temporary work permits and allowed to stay in the country for 6 months. Such migration incentives resulted in a chain migration of Pacific peoples to New Zealand, encouraged by improved transport links, dissatisfaction with island conditions, and job opportunities in New Zealand. As Pacific peoples became established in New Zealand throughout the 1960s and 1970s, chain migration to reunite families became a dominant consideration in the migration process, despite economic uncertainty and reduced employment opportunities in New Zealand. Consequently, during 1973-74, an unprecedented number of immigrants arrived in New Zealand from the Pacific Islands (Ministry of Pacific Island Affairs 1999b). Because the 1960s and early 1970s were years of economic expansion and labour shortages, temporary visas and quotas were not strictly enforced.

Deteriorating economic conditions, with the oil crisis of the mid 1970s, saw a decline into economic recession, with high unemployment resulting in government and public concern about immigration levels. Popular and state-supported racism towards Pacific populations in New Zealand intensified, immigration regulations were tightened, and Pacific people were widely perceived as overstayers who took jobs away from "New Zealanders" (Krishnan et al. 1994). Dawn raids were carried out on the homes of Pacific peoples, with the intention of deporting those without appropriate residency permits. In 1976, an amnesty was reached and many Pacific peoples were granted permanent residency in New Zealand. Free access to New Zealand continued to be granted to those born in the Cook Islands, Niue, and Tokelau. However, allowances towards migrant workers on temporary permits from Western Samoa, Tonga, and Fiji were more tightly controlled.

During the 1980s, a less restrictive immigration policy was adopted by the New Zealand Government, paving the way for more non-European migration. Partly as a result of this, the Pacific population in New Zealand increased eight times faster than the national population between 1986 and 1991. During this time, unemployment rates and social conditions worsened for Pacific Island migrants, adversely affecting their quality of life and health status. The Immigration Amendment Act of 1991 saw the introduction of a points-based immigration policy for migrants to enter New Zealand. This system was implemented to control the number and type of immigrants entering the country. Those with business interests or those who were highly skilled were given preference. During the 1990s, traditional immigration from Pacific countries dropped dramatically. The Samoan Quota Scheme remained in place, however, enabling up to 1100 Samoan citizens to be granted residency in New Zealand each year. 


\section{DEMOGRAPHIC AND SOCIAL CIRCUMSTANCES OF PACIFIC PEOPLES IN NEW ZEALAND}

To appreciate the health status of Pacific peoples in New Zealand it is first necessary to understand the context surrounding Pacific health locally. Amongst other factors, health status is heavily influenced by the quality of health care services, personal income, educational attainment, cultural and social contexts, and housing conditions. Pacific peoples adverse socio-economic conditions, increased health risks, problems in health services utilisation, and transitional demographic characteristics contribute to their poorer health status and impact significantly on the overall health status of the total New Zealand population (Tukuitonga \& Finau 1997).

Recent statistics published by the Ministry of Health (2003a, 2004, 2007) and Statistics New Zealand $(2003,2006)$ illustrate the socio-demographic factors which may contribute to the poorer health status of Pacific peoples living in New Zealand. For example,

- $42 \%$ of Pacific peoples live in the $10 \%$ most deprived areas of the country, with relatively poorer housing and overcrowding

- the participation of Pacific adults in tertiary education is half the national average

- in 2006, the median annual income of all Pacific peoples aged 15 and over was \$20 500, compared to \$24 400 for the total population

- though the rate of unemployment among Pacific peoples is decreasing, it is still double that for the New Zealand European workforce

- $\quad 25 \%$ of Pacific males are factory workers

- $60 \%$ of Pacific peoples residing in New Zealand are New Zealand born, with a median age for the New Zealand born of 11.4 years

- Pacific women had the highest fertility rate in New Zealand at 2.9 in 2001 compared to 2.6 for Maori and 1.8 for other ethnic groups

- $\quad$ over the period 1991-2006, Pacific peoples in New Zealand increased by 59\% from 167000 to 266000 , with emerging risks to child and youth health status.

Krishnan et al. (1994) describe Pacific peoples as having become an "entrenched underclass" within New Zealand society, with increased marginalisation and discrimination, both socially and economically. Added cultural pressures include expectations to provide for non-migrant family members back home and for the church. More recent trends suggest improved mobility and education status among locally born Pacific people and a move away from low-skilled and low-income occupations (Davis et al. 2005; Ministry of Pacific Island Affairs 2006). Traditionally, however, socio-economic pressures have had significant and debilitating influence on the Pacific population's health status.

\section{HEALTH DEVELOPMENTS OVER THE DECADES}

\section{0-60s}

Very little information is available on the socio-demography, health status, or health developments of Pacific peoples before the late 1960s, given the limitations of the collection of health data at that time. There is some evidence to indicate a high incidence of measles during the 1950s amongst Pacific children (Cullen \& Walker 1996). However, the most fruitful 
information comes from the 1968-71 Tokelau Island migrant studies led by Ian Prior, Director of the Epidemiology Unit at Wellington Hospital (Prior 1972). For example, data published by Beaglehole (1975) suggest that migration from Tokelau to New Zealand had a deleterious effect on child health and that at least some of the risk factors for coronary heart disease were changing for the worse. Beaglehole attributed the changes in child health to post-migration weight gain and obesity. For the adult population, Harding (1975) found that Tokelauan migrants had eating patterns closer to the eating patterns of the "New Zealanders" with whom they mixed, and concluded that major dietary changes had occurred following migration. Tokelauan migrants to New Zealand showed an increase in chronic illnesses such as varicose veins, hypertension, and heart disease (Pacific Health Research Centre 2003).

\section{0s}

During the early 1970s, the Tokelau Island migrant studies continued to explore the health differences of migrant and non-migrant Tokelauans (Davidson 1975; Harding 1975; Prior 1975; Stanhope 1975; Tonkin 1975; Hooper et al. 1992). The most striking difference in disease status between Tokelau residents of New Zealand and the population remaining in Tokelau was found in asthma rates. A past history of asthma was common to approximately $10-16 \%$ of Tokelau adult migrants, yet asthma as a current health problem was rare in Tokelau, affecting only $1 \%$ of the population. Asthma affected $9 \%$ of males and $5 \%$ of females in the general New Zealand population. Stanhope (1975), however, concluded that, apart from asthma, changes attributable to migration were generally "unimpressive" at this stage. Definitive data on health disparities were lacking.

As the Tokelau Island migrant studies progressed and more data became available, Prior et al. (1977) found Tokelauan children living in New Zealand had high prevalence of ear and chest infections, asthma, purulent skin lesions, and eczema compared to their non-migrant counterparts. Prevalence of diabetes in adults increased from $6.1 \%$ in women and $2.3 \%$ in men before migration in 1968-71 to $10.8 \%$ and 4.4\%, respectively, by 1976 (Simmons 1997).

Some Pacific families reported difficulty in accessing health services, perceived barriers including language and cultural attitudes (Christmas 1970). Ethnic-specific health services within the mainstream health sector were largely non-existent for Pacific peoples during the 1970s. Such needs were recognised by a small handful of individuals who were keen to remedy many of the difficulties experienced by Pacific families trying to access health care. For example, in 1975, PACIFICA was established to cater for Pacific women's welfare and in 1978, Dr Leopino Foliaki and Dr Papalii Semisi Maiai established Pacific Health Welfare.

\section{0s}

By the beginning of the 1980s, mortality and morbidity statistics were beginning to show the disparity between Pacific and Palagi ethnic groups (Public Health Commission 1994). For example, in 1983, the impact of diabetic nephropathy among Pacific peoples was first shown at Middlemore Hospital. Chronic renal failure was reported to be present in $1 \%$ of diabetic Palagi but in $28 \%$ of diabetic Pacific people. Hospitalisation rates for Pacific children during the 1984/85 measles epidemic were 20 times those of Palagi children. Between 1987 and 1991, Pacific children aged between 1 and 4 were hospitalised for pneumonia at three times the rate for all children in this age group. Pacific children also had high hospitalisation rates for asthma, acute respiratory infections, infectious and parasitic diseases, burns, and unintentional injuries 
due to motor vehicle crashes. Pacific adults showed relatively higher hospitalisation rates than non-Pacific peoples for unintentional injuries, asthma, acute respiratory infections, pneumonia, cancer, infectious and parasitic diseases, and diabetes (Public Health Commission 1994).

In government, a response to the escalating negative statistics amongst Pacific peoples was beginning to emerge. In 1983, Richard Prebble was appointed New Zealand's first Minister of Pacific Island Affairs, which was shortly followed by the establishment of the Pacific Island Affairs Unit in 1984 and the Minister of Pacific Island Affairs' Advisory Council in 1985. This latter development formed the platform for Pacific policy and planning. Major restructuring within the state sector took place during the latter part of the 1980s (Barnett \& Barnett 2005), paving the way to allow non-government organisations to contract for health service delivery.

Recognition that the values, beliefs, and behaviour embedded in the New Zealand health care system reflected the wider Palagi cultural context brought recognition that this could be disempowering for Pacific peoples, particularly those who spoke only their native tongue (Lurch 1989). During the late 1980s, there was increased pressure to establish culturally appropriate health care services for Pacific people (Tukuitonga 1999). Consequently, the first translation service was established for Pacific peoples at Middlemore Hospital and, in 1989, Auckland-based Pasifika Healthcare was established. Pasifika Healthcare was the first primary care health service specifically designed, owned, managed, and provided by and for Pacific peoples in New Zealand, made possible by new government policy initiatives and the contractual purchasing of community services. The community owned not-for-profit service was initiated by community leaders and Pacific health professionals in response to concerns about the availability of culturally appropriate general health care services for Pacific people in New Zealand (Tukuitonga 1999).

\section{0s}

Heath and socio-demographic disparities between Pacific, Maori, and Palagi ethnic groups in New Zealand were becoming more evident by the early 1990s. For example, in 1991, the average number of people per Pacific household was 4.2 compared with the national average of 2.8. In 1994, unemployment reached 23\% amongst Pacific peoples, compared to $9.5 \%$ of the total labour force. Conversely, this decade was also characterised by an increased participation of Pacific peoples in politics, education, unions, professional occupations, sport, and in the arts (Ministry of Health 2003b).

Despite longstanding problems in the definition and recording of ethnicity, statistics during the 1990s highlight the much poorer health status of Pacific peoples than the Palagi population. For example, the prevalence of rheumatic fever between 1990 and 1995 for Pacific children aged 10-14 was 77.7 per 100 000, 30.4 per 100000 for Maori children compared with 1 per 100000 for Palagi children (Ministry of Health 1996). In 1996, children of Pacific origin were six times more likely to be admitted with pneumonia than children of other New Zealanders (Pati et al. 1996). Meningococcal meningitis was also becoming a major problem for Pacific children under the age of 1, with incidence rates of 32.9 per 100000 for Pacific, 13.7 per 100000 for Maori, and 7.9 per 100000 for Palagi (Ministry of Health 1996). By 1995, analyses of cancer rates by North Health (Tantrum et al. 1995) indicated Pacific peoples, compared to the rest of the population (excluding Maori), had twice the hospitalisation rate for cervical cancer, three times the rate of liver cancer, and higher rates for prostrate and stomach 
cancer. Ischaemic heart disease was the largest contributor to avoidable mortality in 1996-97 while diabetes was the second largest contributor (Public Health Commission 1994; Ministry of Health 1996, 1997, 1998). Overall, such evidence suggested a pattern of severe illness at hospital admission, a tendency to present late, and admission (and re-admission) for preventable and manageable conditions such as high blood pressure, diabetes, asthma, hepatitis B, and injuries (Edwards 1996).

During the mid 1990s, there was growing and compelling concern that the overall Palagi style of health care service provision was often ineffective and inadequate for Pacific peoples. Statistics revealed Pacific people were under-utilising health services in New Zealand, and the large majority of Pacific people were being served by non-Pacific health professionals. Various studies found Pacific people had a lower rate than Palagi people of the use of primary care services, such as GP visits and filing prescriptions, despite research revealing that 19\% of Pacific peoples reported their health as being "not so good" or "poor" compared to $8 \%$ of Palagi (Ministry of Health 1996). Pacific peoples were also presenting late and did not appear to derive comparable benefits from healthcare services as did the general population (Ministry of Health 1996). Barriers to the utilisation of health care included a lack of awareness of or discomfort with primary care services, cost, transport, language and communication difficulties, cultural norms and health beliefs, and a preference for traditional medicines and healers (Public Health Commission 1994; Tofi 1996).

In 1997, the then Health Minister, Bill English, indicated at the inaugural Pasifika Conference that traditional health practices in New Zealand had failed Pacific peoples, and provided a commitment by the government to improve Pacific health services. A Chief Advisor Pacific Health was appointed by the Ministry of Health and a joint venture between the Ministry of Health and the Ministry of Pacific Island Affairs produced the first national strategy, Making a Pacific Difference: Strategic Initiatives for the Health of Pacific People in New Zealand (Ministry of Health 1997). Following this, and under the leadership of Debbie Sorensen, the first Chief Advisor Pacific Health, the Ministry of Health (1998) published Making a Pacific Difference in Health Policy, which identified key result areas envisaged as the focus of Pacific health policy over the next 3 years. Pacific health research also became a priority during the late 1990s with the establishment of two Pacific Island Health Research Centres in Wellington and Auckland, funded by the Health Research Council and other government funding agencies to promote and enhance health research related to Pacific people.

A major and contentious policy initiative of the 1990s in New Zealand was the radical restructuring of the health system (Lima 1999; Hornblow \& Barnett 2000; Barnett \& Barnett 2005). One of the positive aspects of such reform was the opportunity to establish ethnicspecific primary health services through government-funded contractual arrangements (Barnett $\&$ Barnett 2005). As such, Pacific communities were able to establish Pacific-specific health services which were potentially better suited to these communities (Tukuitonga 1999). One of the major obstacles in achieving this was the lack of management skills within the Pacific community to establish a health organisation and the shortage of Pacific people who were qualified in a health-related discipline. Despite such difficulties, several clinical practices were established during the 1990s to cater for Pacific needs, including the Langimalie Health Centre, Healthstar Pacific, Pasifika Fono, Otara Health, South Seas Health, and South Seas Kids, all in Auckland, South Waikato Pacific Islands Health, K'aute Pasifika in Hamilton, Pacific Health in Naenae, Pacific Trust Canterbury, and the Otago Pacific Peoples Health Trust. 
One of the major themes emerging from this decade was the importance of health education material being targeted to specific populations, communicated in their own language and cultural context (Ministry of Health 1996).

Another theme was the emergence of health workers of Pacific ethnicity. For example, Pacific-oriented strategies to reduce the incidence of rheumatic fever included school and community-based health education campaigns around the message "sore throats matter", including the South Auckland Schools Study which focused on sore throat detection and treatment within schools with a high proportion of Pacific students. Strategies initiated by the National Heart Foundation to improve nutrition and physical activity incorporated various health promotion programmes specifically directed at Pacific peoples (Swinburn et al. 1997). The Alcohol Advisory Council developed a Pacific programme, with health promotion resources in six Pacific languages and training awards to address the growing problem of alcohol abuse (Wilson 2000).

Despite these government and community initiatives to improve the health of Pacific peoples, Tukuitonga (1999: 10) concluded that "over-representation of Pacific people in hospital discharge statistics could be attributed to lower primary care utilisation ... efforts to improve access to primary medical care service do not appear to be effective ... Financial, social, language, and cultural factors are likely to be important barriers but objective information on their relative importance ... is not available".

\section{0-Present}

As an important strategic initiative, the Ministry of Health established the Pacific Health Branch in 2000, composed of a team of analysts dedicated to improving the health of Pacific peoples in New Zealand. In 2002, the first Cabinet-approved Pacific Health and Disability Action Plan was launched and implemented by the Ministry of Health. Again, this was an official move to recognise that health policies designed for a Palagi population did not sufficiently address the health problems and needs of Pacific peoples living in New Zealand.

Continuing health disparities, documented in the Pacific Health Chart Book (Ministry of Health 2004), indicated mortality rates for Pacific adults to be higher than those for Palagi, including rates for cardiovascular disease and cancer. Changes in diet and lifestyle were seen to be major factors in the increasing incidence of chronic non-communicable diseases (Pacific Health Research Centre 2003). For many Pacific peoples, the change in diet and the shift from a traditional environment to urban centres has been linked to the increase in dental caries, obesity, hypertension, coronary health disease, gout, diabetes, and cancer (Ministry of Health 1996). Given these wide-ranging health disparities, the Ministry of Health set target areas for improving the health of Pacific peoples, including both non-communicable diseases, particularly diabetes, cardiovascular and respiratory disease, communicable diseases, and mostly childhood diseases such as acute rheumatic fever, infection-induced hearing loss, a number of parasitic and infectious diseases, and sexual and reproductive health. Other areas of concern included alcohol abuse among Pacific males (Alcohol Advisory Council 2004) and the higher rate of psychiatric admissions among Pacific peoples (Ieremia 2003).

One of the themes which emerged during the early 2000s was that of culturally competent health care services and "cultural safety". Jansen \& Sorensen (2002) argued that the lack of cultural understanding between the prevailing health care system and many Pacific patients was reflected in the health disparities between Pacific peoples and Palagi New Zealanders. 
They also claimed that the lack of cultural concordance between Pacific patients and predominantly Palagi health providers presented barriers to appropriate care, in terms of being understandable and understanding to the patient. They went on to suggest that the key factor in improving access to care and adherence to treatment for Pacific peoples is to develop the cultural competence of health care providers, frameworks for which have now been developed by District Health Boards (Foliaki 2005) and others (e.g., Alcohol Advisory Council 2002).

The funding of culturally appropriate clinical support services for Pacific peoples is a relatively recent phenomenon. Much of the observed progress in improved quality and the availability of health care services is related to Pacific Island communities taking charge of their own destinies through self-determination (D Ryan pers. comm.). An example of this selfdetermination can be seen in the controversial meningococcal vaccination campaign where community, church, and health sector collaboration saw the immunisation rates for Pacific children increase exponentially, reducing the incidence of the disease for Pacific infants from 504.2/100 000 in 2003 to 58.2/100 000 in 2005 (Ministry of Health 2006).

By 2000, there were 30 Pacific-owned health provider organisations throughout New Zealand. The Health Funding Authority also established contracts with 24 Pacific churches for health education, health promotion, and exercise programs, as the church is the venue where about $90 \%$ of all Pacific peoples in New Zealand congregate on a regular basis. Several new non-government organisations have been established in the 2000s to fill the need for Pacificspecific services. For example, in 2000, Pacific Health Service Wellington was established under a government contract and became independent in 2002. This nurse-led mobile primary health service emphasises free family care and support for Pacific peoples in the Wellington region, visiting schools, community centres, and church halls. TaPasefika Health Trust commenced in September 2002 to improve the health and wellbeing of Pacific peoples, families, and communities. Health Pacifica, South Seas Healthcare, and Health Star Pacific are three Pacific health providers which fall under the Trust's umbrella in the Mangere and Otara region. The Trust was set up to take advantage of the opportunity in the Primary Health Care strategy to improve the health of disadvantaged populations in South Auckland, particularly Pacific peoples (McElroy 2002). In 2003, the Auckland District Health Board worked with the Tongan Health Society to register their Langimalie clinic as a Public Health Organisation, which provided access to additional funding and the commencement of many healthcare improvement initiatives.

A significant health sector theme in the 2000s, after the turbulence of the health reforms of the 1990s, has been the focus on health workforce development, including the need to increase the capacity and capability of Pacific health workers (Health Workforce Advisory Committee (HWAC) 2003). Following extensive consultation and a national health workforce summit in March 2003, HWAC forwarded comprehensive recommendations for the development of the New Zealand health workforce to the Minister of Health. One of the six priority areas was the development of the Pacific workforce, with recommendations to foster, by District Health Boards, Pacific provider capacity and capability and to strengthen the collaboration between the Ministries of Health, Pacific Island Affairs, and Education. Other workforce-related initiatives have included support for regional and national Pacific networks and the Pacific Provider Development Scheme set up to develop Pacific health providers' business skills to ensure they are better placed to participate fully in the development of the health sector in the future. 
To date, we know little of how effective these initiatives have been in improving the health status of Pacific peoples in New Zealand. Some evidence suggests that positive results have been seen in areas such as the success of the meningococcal B immunisation programme, improved access for Pacific peoples to primary health care services, the strengthening of Pacific health service providers, and the fact that Pacific peoples have a high rate $(96 \%)$ of registration with Primary Health Organisations (Ministry of Health 2004; Ministry of Health and Minister of Health 2007). However, further data are needed to determine whether initiatives in Pacificbased health services over the past decade have lead to improved health outcomes.

\section{INTO THE FUTURE...}

Health systems evolve over time. Factors influencing this evolutionary process - an increasingly rapid one in recent decades - include changing health needs and expectations, varying resource capacity and constraints, and diverse and sometimes competing political and community pressures. The New Zealand health system is no exception. Unlike some other health systems, however, New Zealand has a largely taxation-based system for funding health services and centrally controlled strategic development. As a consequence, responsibility for identifying and responding to changing health needs in the New Zealand population is seen to lie largely with central government, the Ministry of Health and health-provider organisations (notably the District Health Boards), which are required to operate within a national health policy framework. Addressing the health needs of ethnic minorities, or other sub-populations, therefore requires acknowledgement that "one size does not fit all", and commitment to flexibility and diversity within a largely centrally controlled health sector. The balance between central control and diversity in service delivery is an ongoing challenge in the New Zealand health system.

Pacific peoples, $0.1 \%$ of the New Zealand population in 1945 , now comprise $6.5 \%$ of the resident population and are projected to be $12 \%$ by 2051 . With a younger demographic profile, Pacific peoples will play an increasingly significant role in the national workforce, including the health workforce. The context of everyday life for Pacific peoples in New Zealand, who have been attracted to New Zealand by the prospect of employment, and welcomed as a solution to workforce shortages in unskilled and semi-skilled occupations, has been one of relative socio-economic disadvantage. Improved documentation of their health status over the last decade or so has consistently shown poorer health across a range of health indicators and greater difficulty in accessing appropriate health care.

A number of developments during and since the 1990s have begun the process of addressing the health needs of Pacific peoples more explicitly and appropriately than in earlier decades. Improved data on the health status and health needs of the various Pacific groups resident in New Zealand have helped set priorities for preventive and health care initiatives. Targeted funding has facilitated the development of a range of Pacific-owned health provider organisations. In mainstream services, there is now a growing acceptance of the importance of providing clinical services which meet defined standards of cultural safety and competence. The establishment of translation services recognises the importance of effective and culturally appropriate communication. There is also increased recognition of the role of traditional healers and Pacific community leaders, given the growing acceptance of the wider context of the social, cultural, and spiritual determinants of health and wellbeing. 
These developments are encouraging but must be sustained and built on if health inequalities are to be reduced and the health status of Pacific peoples improved. Strong Pacific leadership and an expanded Pacific health workforce will be crucial factors in addressing current and emerging health needs, along with effective working partnerships between Pacific providers and the wider health sector. Beyond the provision of clinical services, and of even greater importance from a preventive perspective, is the need to grasp the shared challenge of reducing lifestyle-related health risks - a challenge both for Pacific communities and New Zealand society as a whole.

\section{ACKNOWLEDGMENTS}

This research was supported by a grant from the Ministry of Health, as part of the Pacific Health Leadership Development Programme. We are grateful for the support of and useful comments from our Pacific colleagues in the health sector, in particular Dr Debbie Ryan, Chief Advisor, Pacific Health. The views expressed in this paper are those of the authors.

\section{REFERENCES}

Alcohol Advisory Council 2002. Practitioner competencies for Pacific alcohol and drug workers working with Pacific clients in Aotearoa New Zealand. Wellington, ALAC Occasional Publication.

Alcohol Advisory Council 2004. Pacific Spirit '04: Rising Pacific waves. Proceedings of the Fourth Biennial Pacific Spirits Conference, Waipuna Conference Centre, Auckland, 3-4 March.

Barnett P, Barnett R 2005. Reform and change in health service provision. In: Dew K, Davis P ed. Health and society in Aotearoa New Zealand. Melbourne, Oxford University Press.

Beaglehole R 1975. Tokelau Island children's study. In: Stanhope J ed. Migration and health in New Zealand and the Pacific. Proceedings of a seminar on migration and related social and health problems in New Zealand. Wellington, Epidemiology Unit, Wellington Hospital.

Christmas B 1970. The inter-action of a personal health service with Maori and Pacific Islander families in central Auckland. Unpublished Doctoral thesis, University of Otago, Dunedin, New Zealand.

Cullen R, Walker W 1996. Measles epidemics 1949-1991: the impact of mass immunisation in New Zealand. New Zealand Medical Journal 109(1032): 400-402.

Davidson F 1975. The Tokelau Island migrant study: atoll diet. In: Stanhope J ed. Migration and health in New Zealand and the Pacific. Proceedings of a seminar on migration and related social and health problems in New Zealand. Wellington, Epidemiology Unit, Wellington Hospital.

Davis P, Suaalii-Sauni T, Lay-Yee R, Pearson J 2005. Pacific patterns in primary health care: a comparison of Pacific and all patient visits to doctors. The national primary medical care survey: 2001/02. Report 7. Wellington, Ministry of Health.

Edwards D 1996. The classification of Pacific Islands ethnicity in New Zealand health data-a case of applied anthropology. Unpublished Masters thesis, The University of Auckland, Auckland, New Zealand.

Foliaki L 2005. Pacific cultural competencies framework. Draft 4. Auckland, Counties-Manukau/Waitemata/Auckland Central District Health Boards.

Harding W 1975. The diet of Tokelau Island migrants in New Zealand. In: Stanhope J ed. Migration and health in New Zealand and the Pacific. Proceedings of a seminar on migration and related social and health problems in New Zealand. Wellington, Epidemiology Unit, Wellington Hospital.

Health Workforce Advisory Committee 2003. The New Zealand health workforce: future directions - recommendations to the Minister of Health 2003. Wellington, Health Workforce Advisory Committee.

Hooper A, Huntsman J, Prior I, Salmond C 1992. Migration and health in a small society: the case of Tokelau. Oxford, England, Clarendon Press. 
Hornblow A, Barnett P 2000. A turbulent decade: lessons from the "Health Reforms". New Zealand Medical Journal 113: 133-134.

Ieremia M 2003. Assessing mental health needs of Hamilton's Pacific Island communities. Unpublished Masters dissertation, The University of Auckland, Auckland, New Zealand.

Jansen P, Sorensen D 2002. Culturally competent health care. New Zealand Family Physician 29(5): 306-311.

Krishnan V, Schoeffel P, Warren J 1994. The challenge of change: Pacific Island communities in New Zealand 1986-1993. Christchurch, Institute for Social Research and Development Ltd.

Lima I 1999. The impact of the health reforms and health research on Pacific people in New Zealand. Unpublished Masters thesis, The University of Auckland, Auckland, New Zealand.

Lurch T 1989. Is our health system for us too? New Zealand Health and Hospital Nov/Dec: 12-13.

McElroy J 2002 Communities stamp identity on primary health organizations. New Zealand Pharmacy November 2002: 8-9.

Ministry of Education 2001. Pasifika education research guidelines. Auckland, Auckland Uniservices Ltd.

Ministry of Health 1996. Pacific Island health information. Wellington, Ministry of Health.

Ministry of Health 1997. Making a Pacific difference: strategic initiatives for the health of Pacific peoples in New Zealand. Wellington, Ministry of Health.

Ministry of Health 1998. Making a Pacific difference in health policy. Wellington, Ministry of Health.

Ministry of Health 2003a. Decades of disparity: ethnic mortality trends in New Zealand 1980-1999. Wellington, Ministry of Health.

Ministry of Health 2003b. Pacific health in New Zealand: our stories. Wellington, Ministry of Health.

Ministry of Health 2004. Tupu ola moui. Pacific health chart book. Wellington, Ministry of Health.

Ministry of Health 2005. The health of Pacific peoples. Wellington, Ministry of Health.

Ministry of Health 2006. The epidemiology of meningococcal disease in New Zealand in 2005. Wellington, Ministry of Health.

Ministry of Health and Minister of Health 2007. Health and independence report 2007. Wellington, Ministry of Health.

Ministry of Pacific Island Affairs 1999a. Pacific analysis framework: analysing public policy through Pacific lenses. Wellington, Ministry of Pacific Island Affairs.

Ministry of Pacific Island Affairs 1999b. Pacific vision: social and economic report. Wellington, Ministry of Pacific Island Affairs.

Ministry of Pacific Island Affairs 2006. Pacific progress 2002-2006: a report on the economic status of Pacific peoples in New Zealand. www.minpac.govt.nz/publications_specialreports_pacificprogress. htm [accessed 13 April 2008].

Pacific Health Research Centre 2003. Pacific Island Primary HealthCare utilisation study. Auckland, University of Auckland.

Pati A, Tan D, Aickin R and others 1996. Ethnic comparisons of disease severity in children hospitalised with pneumonia. Summer student report to the Health Research Council of New Zealand.

Prior I 1972. The Tokelau Islands migrant study. In: Stanhope J, Dodge J ed. Migration and related social and health problems in New Zealand and the Pacific 1972. Wellington, Epidemiology Unit, Wellington Hospital.

Prior I 1975. The Tokelau Island migrant study. In: Stanhope J ed. Migration and health in New Zealand and the Pacific. Proceedings of a seminar on migration and related social and health problems in New Zealand. Wellington, Epidemiology Unit, Wellington Hospital.

Prior I, Hooper A, Huntsman J, Stanhope J, Salmond C 1977. The Tokelau Island migrant study. In: Harrison $\mathrm{G}$ ed. Population structure and human variation. Cambridge, England, Cambridge University Press. Pp. 165-186.

Public Health Commission 1994. The health of Pacific Islands people in New Zealand. Wellington, Public Health Commission. 
Simmons D 1997. Diabetes and its complications among Pacific people in New Zealand. Pacific Health Dialog 4(2): 75-79.

Stanhope J 1975. The Tokelau Island migrant study: disease prevalence among residents in the atolls and New Zealand. In: Stanhope J ed. Migration and health in New Zealand and the Pacific. Proceedings of a seminar on migration and related social and health problems in New Zealand. Wellington, Epidemiology Unit, Wellington Hospital.

Statistics New Zealand 2003, 2006. http://www.stats.govt.nz/census/default.htm [accessed 13 April 2008].

Swinburn B, Amosa H, Bell C 1997. The Ola Fa'autauta Project: developing a church-based health programme. Pacific Health Dialog 4(2): 20-26.

Tantrum M, Twitchin S, Jackson G 1995. Mortality and morbidity. Report for North Health: an analysis of the northern region by district and ethnicity. Auckland, North Health.

Tofi T 1996. The use of health care services by Pacific Islands people in New Zealand. Unpublished Masters thesis, Massey University, Palmerston North, New Zealand.

Tonkin S 1975. Tokelau Island children's study: common diseases. In: Stanhope J ed. Migration and health in New Zealand and the Pacific. Proceedings of a seminar on migration and related social and health problems in New Zealand. Wellington, Epidemiology Unit, Wellington Hospital.

Tukuitonga C 1999. Primary healthcare for Pacific people in New Zealand. Discussion paper for the National Health Committee. Wellington, Ministry of Health.

Tukuitonga C, Finau S 1997. The health of Pacific peoples in New Zealand up until the 1990s. Pacific Health Dialog 4(2): 59-67.

Wilson T 2000. "Alcohol affects everybody!” An evaluation of the pamphlet and poster series developed for use with Pacific Islanders. Unpublished study prepared for the Pacific Islands Drug and Alcohol Services (PIDAS). 